\title{
AGRICULTURA FAMILIAR AGROECOLÓGICA EM ITAPEJARA D’OESTE-PR
}

\author{
Marcos Aurélio Saquet \\ Bolsista Produtividade CNPq \\ Prof. da Unioeste - Francisco Beltrão \\ saquetmarcos@hotmail.com \\ Poliane de Souza \\ poliane_nardi@hotmail.com \\ Roseli Alves dos Santos \\ roseliasantos@gmail.com
}

\begin{abstract}
Resumo
Este texto apresenta reflexões sobre a realidade pesquisada a partir da realização do projeto de pesquisa e extensão sobre a prática da agroecologia no município de Itapejara d'Oeste, para isso descrevemos e analisamos a prática agrícola desenvolvida por agricultores familiares que produzem de forma agroecológica ou que buscam uma aproximação desta forma de produção. Buscamos ainda demonstrar a importância da produção agroecológica como uma forma de alternativa de produção e renda frente ao modelo convencional.
\end{abstract}

Palavras-chave: agroecologia, sudoeste do Paraná, agricultura familiar.

\begin{abstract}
The texto presents some observations on the real facts researched from the project of extension about the practice of agroecology in the county of Itapejara d'Oeste. To make it possible we have described and analyzed the gricultural practices developed by family farmers who produce in a agroecological way or who seek to be close of an agroecological production. We still have tried to demonstrate the importance of agroecological production as an alternative of production and income facing up to the concentional model of agriculture.
\end{abstract}

Key Words: agroecology, south wat of Parana, family agriculture

\section{INTRODUÇÃO}

Os processos de inovações industriais ocorridos no âmbito urbano no século XIX tiveram uma fase de intensa expansão a partir da I Guerra Mundial e, sobretudo, depois da década de 1950, quando se inicia a implantação de novas técnicas e práticas no espaço rural, as quais ampliam as possibilidades de aumento da produção, a partir do uso de um pacote tecnológico, cujos efeitos promove a chamada revolução verde.

Este modelo de produção se baseia no uso intenso de sementes modificadas, de fertilizantes, de agrotóxicos, além do uso de novas tecnologias desde o plantio até a colheita e a comercialização. Esse pacote, marca a integração dos capitais industrial e agrícola. A meta é desta forma ampliar a acumulação de capital, com o aumento da produtividade, redução dos custos e maximização dos lucros, a partir da chamada modernização da agricultura.

A efetivação dessa modernização acarreta o surgimento de problemas de ordem social, econômica e ambiental, além de potencializar outros já existentes, em virtude do uso do pacote tecnológico e da lógica produtiva imposta pelo modelo. No que se refere à questão ambiental, os problemas provocam a contaminação dos recursos hídricos e dos animais; erosão; contaminação dos solos e redução da sua fertilidade natural; redução da biodiversidade; dependência de insumos químicos. Impactos em outras dimensões territoriais também são visualizados, como a concentração fundiária; o êxodo rural, entre outros, que estão cada vez mais visíveis e presentes no espaço rural. 
A partir dos problemas decorrentes da produção convencional, procura-se encontrar soluções alternativas que minimizem tais impactos. Uma destas alternativas é a agroecologia. Segundo Gliessman (2001), nos anos 1930, alguns ecologistas propuseram o termo agroecologia para designar a ecologia aplicada à agricultura. Assim, nasciam as bases de uma forma de produção agrícola, realizada em pequenas propriedades diversificadas ou em estabelecimentos maiores com base na monocultura.

Desse modo, é importante diferenciar a agroecologia da produção orgânica, pois, muitas vezes, elas são tratadas como análogas, porém, existem diferenças entre essas duas alternativas de produção agrícola.

A agroecologia dedica-se ao estudo das relações produtivas existentes entre a sociedade e a natureza, visando sempre a sustentabilidade ecológica, econômica, cultural, política e ética. As práticas agroecológicas se baseiam na pequena propriedade, na mão-de-obra familiar, em sistemas produtivos complexos e diversos, adaptados às condições locais e em redes regionais de produção e distribuição de alimentos.

Já na produção orgânica não se utilizam produtos químicos sintéticos ou alimentos geneticamente modificados, no entanto, esta produção não está isenta de ser efetivada nos moldes da agricultura convencional ou da monocultura, os produtores apenas não fazem uso de insumos químicos. Como se trata de uma produção diferenciada, alcança maiores valores de comercialização. Um dos destaques é a produção de grãos para exportação, como a soja.

Nas últimas décadas, as áreas de terras geridas ecologicamente e o número de produtores aumentaram consideravelmente em vários países do mundo: segundo dados de 2009, da Federação Internacional dos Movimentos de Agricultura Orgânica (IFOAM), mais de 140 países possuem terras geridas organicamente. Em 2007, na América Latina, existiam aproximadamente 220.000 produtores orgânicos cultivando cerca de 6,4 milhões de hectares de terras. A maioria da produção orgânica na América Latina é destinada para exportação, tais como as frutas tropicais, grãos e cereais, café, cacau, açúcar e carnes.

Em reconhecimento da crescente importância da produção orgânica para a economia agrícola muitas instituições governamentais, na América Latina, começaram a desempenhar um papel central na promoção dessa agricultura. No Brasil, por exemplo, dentre algumas iniciativas, está o apoio a programas e projetos de desenvolvimento da agricultura agroecológica e orgânica, como ocorreu no Sudoeste do Paraná com as ações da Associação de Estudos, Orientação e Assistência Rural (ASSESOAR) e do Centro de Apoio a Pequenos Agricultores (CAPA). É neste contexto que desenvolvemos, desde abril de 2009, um projeto de pesquisa e extensão envolvendo a Universidade Estadual do Oeste do Paraná (Unioeste) e alguns parceiros, como as entidades mencionadas anteriormente.

O projeto "Agricultura familiar agroecológica nos municípios de Verê, Itapejara d'Oeste e Salto do Lontra (Sudoeste do Paraná), como estratégia de inclusão social e desenvolvimento territorial", é financiado com recursos da Secretaria Estadual de Ciência, Tecnologia e Ensino Superior do Paraná (SETI) através do Programa Universidade Sem Fronteiras (USF). Neste texto, apresentamos os principais resultados obtidos até o momento no município de Itapejara D'Oeste (PR).

Para efetivar as atividades do projeto, optamos pela metodologia participativa desde a coleta dos dados, passando pela discussão da metodologia até o planejamento e realização das ações voltadas à prática agroecológica. Nossos objetivos principais são compreender as características da produção agroecológica, participar através das atividades de extensão e cooperação na qualificação dessa produção, contribuir com a geração de empregos, identificar as prioridades e viabilizar cursos de capacitação e formação. Para atingir esses objetivos, trabalhamos com os seguintes procedimentos: pesquisa bibliográfica, coleta e análise de dados secundários (IBGE), realização de entrevistas a partir de um roteiro previamente definido, elaboração de quadros sínteses, mapeamento da produção agroecológica, organização de relatórios e realização de reuniões mensais de planejamento e avaliação. 
Os conceitos que servem de orientação para a pesquisa e as ações de extensão-cooperação são os seguintes: território, desenvolvimento, agricultura familiar, agroecologia, redes, cooperação e inclusão social, conforme apresentamos inicialmente em Saquet et al (2010). Acreditamos que, para reorganizar a produção, a forma de vida e o território, é necessário repensar e reorganizar as relações de poder, valorizando e reforçando pequenas organizações políticas, culturais e produtivas. A agroecologia, entendida como uma alternativa de desenvolvimento vinculada à conquista de autonomia, requer novas relações dos homens entre si e com a natureza; o manejo adequado do solo, das plantas e das águas; relações participativas de cooperação; eliminação de intermediários e valorização dos produtos primários e do patrimônio identitário, enfim, envolve um jeito específico de produzir e viver num movimento de contraponto à racionalidade do capital, conforme indica Saquet (2007).

E isto exige uma compreensão e atuação por parte do pesquisador-sujeito político, que considere os processos sociais (econômicos, políticos e culturais) e naturais, tanto na abordagem (estudo) como no planejamento e nas ações a serem realizadas com os agricultores familiares. Há destaque para o lugar, para a dinâmica ambiental e para a elaboração de projetos de desenvolvimento com base em pequenas iniciativas. A sustentabilidade é pensada para além da proteção da natureza, incorporando o território, ou seja, a sustentabilidade do conjunto de seus componentes.

Isto significa que compreendemos o desenvolvimento como multidimensional, ou seja, processo de conquistas qualitativas nos âmbitos econômico, político, cultural e ambiental. A natureza é um patrimônio territorial e precisa ser gerida pela sociedade local articulada a outros grupos sociais, com capacidade de autogestão, valorizando a ajuda mútua, o pequeno comércio, a autonomia, o trabalho manual do agricultor, os saberes populares, a cooperação, o patrimônio identitário, a biodiversidade, as microempresas, enfim, a vida.

\section{A AGROECOLOGIA NO MUNICÍPIO DE ITAPEJARA D’OESTE - PR}

A agricultura agroecológica começou a ser efetivada no município por volta dos anos de 2001-2002, por iniciativa da Secretaria Municipal da Agricultura e Meio Ambiente em parceria com o Centro de Apoio ao Pequeno Agricultor (CAPA) e a Instituto Paranaense de Assistência Técnica e Extensão Rural - Emater

O CAPA é uma organização não governamental ligada a Igreja Evangélica de Confissão Luterana no Brasil (IECLB), com sede na Alemanha. Dos cinco núcleos da ONG no Brasil , dois estão no Paraná, um em Marechal Cândido Rondon e outro no município de Verê, oferecendo assistência e orientação aos agricultores dos municípios de cada região.

De acordo com o Engenheiro agrônomo Joacir Citadim, da Secretaria de Agricultura e Meio Ambiente de Itapejara, a instituição começou atuar com a agroecologia em parceria com o CAPA, núcleo de Verê, e a Emater, dando assistência aos produtores no processo de conversão das propriedades. A parceria consistia, principalmente, em visitas para divulgar a produção agroecológica, sua importância e técnicas de cultivo.

Durante o período de parceria, aproximadamente noventa produtores foram capacitados para produzir de forma agroecológica. Porém, atualmente, este número não ultrapassa dez produtores que continuam com a produção. $\mathrm{O}$ trabalho do CAPA permanece com alguns viticultores que vendem uva para a fábrica de sucos orgânicos de Verê, denominada Sucos Viry.

Em 2009, a Cooperativa de Crédito Rural com Interação Solidária (CRESOL), institui uma entidade para pratica de assistência técnica e extensão rural (ATER), com o objetivo de terceirizar a preparação dos projetos e viabilizar, para os agricultores, o acesso aos financiamentos do Pronaf Investimento e/ou Custeio. Essa entidade elabora projetos para mais de 500 agricultores do Sudoeste do Paraná, além disso fornece assistência técnica para aproximadamente 100 famílias. A atuação da ATER ainda é recente, mas

Revista da ANPEGE. v. 6, 2010 (jan./dez.) 
possui alguns projetos em Itapejara como, por exemplo, a promoção da fruticultura, investindo principalmente no cultivo de cítricos, pois estes possuem maior adaptação às condições ambientais locais.

A CRESOL é uma cooperativa solidária presente em muitos municípios da região Sul do Brasil, cujos objetivos são trabalhar em prol da agricultura familiar e do pequeno produtor auxiliando com financiamentos e outros benefícios. Em Itapejara d'Oeste, ela está presente desde o ano de 2001 e atua indiretamente na agroecologia desde o início da sua fundação através de financiamentos de custeio e investimento. As principais ações realizadas estão vinculadas aos financiamentos para a construção de estufas e outras estruturas, e apoiando tecnicamente atividades para a proteção de nascentes d'água.

Apesar do envolvimento dessas instituições, a produção agroecológica em Itapejara tem um incremento bastante lento. De acordo com dados de 1995, do IBGE, o município possui aproximadamente 983 estabelecimentos agropecuários em condição legal de posse (93\% são propriedades com menos de 50 ha), destes apenas nove (cerca de 1\%) são os que possuem algum tipo de produção agroecológica, como mencionamos anteriormente. Alguns dos motivos que estão relacionados a este baixo interesse dos agricultores serão tratados mais especificadamente a seguir.

\section{ASPECTOS DA PRODUÇÃO AGROECOLÓGICA}

No município de Itapejara d'Oeste são nove os produtores envolvidos pelo projeto em questão. As propriedades apresentam área média de 17,14ha (Tabela 1) sendo que a área média destinada à agroecologia é de 3,8ha. As propriedades são pequenas, mas possuem uma boa diversificação de culturas conforme verificamos no trabalho de campo. A gestão e a força de trabalho dos estabelecimentos são exclusivamente familiares. A mão-de-obra utilizada (Tabela 1), em algumas propriedades, é limitada apenas ao casal; em algumas há a participação direta dos filhos que residem na propriedade; quando há excesso de tarefas e a família não consegue dar conta, recebem ajuda dos vizinhos trabalhando em regime de troca de dias de serviço. Este sistema é muito comum em pequenas propriedades de Itapejara, pois o custo para contratar trabalhadores externos é muito elevado e não compensa para o pequeno produtor agrícola mercantil. Alguns produtores, como é o caso de Raul Dall'Agnol e Milton Moschen, contratam trabalhadores temporários, principalmente durante o período de safra.

Tabela 1 - Produtores de Itapejara d'Oeste- PR

\begin{tabular}{c|c|c}
\hline \multicolumn{1}{c}{ Produtor } & $\begin{array}{c}\text { Tamanho da } \\
\text { Propriedade } \\
\text { (ha) }\end{array}$ & $\begin{array}{c}\text { No de } \\
\text { Trabalhadores }\end{array}$ \\
\hline Antonio Plucinski & 4,8 & $\begin{array}{c}04 \\
\text { (casal e dois filhos) } \\
02 \\
\text { (casal) }\end{array}$ \\
\hline Osmar Franciscon & 8,0 & $\begin{array}{c}02 \\
\text { (casal) }\end{array}$ \\
\hline NiIdo Caldato & 12,5 & $\begin{array}{c}03 \\
\text { (casal e um filho) }\end{array}$ \\
\hline Raul Dall'Agnol & 13,0 & $\begin{array}{c}03 \\
\text { (casal e um filho) }\end{array}$ \\
\hline Nelson Savitski & 13,3 & $\begin{array}{c}02 \\
\text { (casal) }\end{array}$ \\
\hline Nadir Antonioli & 14,0 & $\begin{array}{c}04 \\
\text { (casal e dois filhos) } \\
07\end{array}$ \\
\hline Arsindo C. Colla & 22,0 & $\begin{array}{c}07 \\
\text { (casal, quatro filhos e uma nora) } \\
\text { (casal e um filho) }\end{array}$ \\
\hline Filisbino C.dos & 31,7 &
\end{tabular}

Fonte: Pesquisa de campo, 2009. 
A produção agroecológica é diversificada (Tabela 2), voltada principalmente para as culturas de frutíferas, hortaliças e grãos, além de produtos transformados, como vinhos, doces e conservas

A uva é uma das principais frutíferas cultivadas, ocupando entre 1,0ha e 1,50ha das propriedades. As primeiras mudas para a constituição dos parreirais foram fornecidas pela Prefeitura Municipal, em parceria com o CAPA, que fornecia assistência técnica, com a CRESOL, que auxiliava com financiamentos para a construção das estruturas, e com a empresa Sucoeste, de Santa Catarina que, na época, comprava uva para fazer o beneficiamento e a comercialização.

Alguns anos depois, a empresa Sucoeste entrou em falência deixando os produtores desamparados. Em 2008, com o apoio do CAPA, da CRESOL e da Associação dos Produtores de Vinho do Verê (APROVIVE), abriram a fábrica de sucos Viry que, atualmente, faz o beneficiamento da produção de uvas agroecológicas de Verê e de Itapejara d'Oeste, comercializando o suco por meio da Associação de Produtores Agroecológicos de Verê-PR (APAV). Além do suco fabricado, os produtores fazem doces de uva e vinho colonial/artesanal para comercializar.

Outras frutas (Tabela 2), como as cítricas (laranja, bergamota e limão) e os pêssegos são produzidas em pequenas quantidades nos pomares, essas frutas são destinadas primeiramente para consumo familiar e o excedente é comercializado. A partir das frutas também são produzidas conservas que são vendidas nas residências ou no comércio local pela Cooperativa de Comercialização da Agricultura Familiar Integrada (COOPAFI).

Tabela 2 - Características da produção dos agricultores estudados

\begin{tabular}{c|l}
\hline \multicolumn{1}{c}{ Produtor } & \multicolumn{1}{c}{$\begin{array}{c}\text { Produtos agroecológicos comercializados } \\
\text { (in natura (1) e transformados (2)) }\end{array}$} \\
\hline Antonio Plucinski & $\begin{array}{l}\text { (1) uva, leite } \\
\text { (2) vinho, queijo }\end{array}$ \\
\hline Osmar Franciscon & (1) hortaliças; mandioca; feijão; batata \\
\hline NiIdo Caldato & $\begin{array}{l}\text { (1) hortaliças } \\
\text { (2) cachaça e açúcar mascavo }\end{array}$ \\
\hline Raul Dall'Agno & $\begin{array}{l}\text { (1) milho, soja, feijão, frutas, leite } \\
\text { (2) geléia, conservas }\end{array}$ \\
\hline NeIson Savitski & (1) uva \\
& (2) vinho \\
\hline Nadir Antonioli & (1) uva \\
\hline Arsindo C. Colla & (1) uvinho \\
\hline Filisbino Cirino dos & (1) hortaliças (alface, beterraba, brócolis, cenoura, couve flor e repolho); frutas \\
Santos & (laranja, limão, bergamota); feijão; mandioca e batata doce \\
\hline Milton Moschen & (1) hortaliças; frutas (uva, laranja, pêssego) \\
\hline
\end{tabular}

Fonte: Pesquisa de campo, 2009.

Além de frutas, também cultivam hortaliças e grãos. Diferentemente dos grãos, o plantio das hortaliças não exige grandes áreas, podendo ser feito em diferentes épocas do ano, permitindo mais de uma colheita. A alface e o repolho, por exemplo, após sessenta dias da semeadura, estão prontos para o consumo. Já na produção de grãos o período do plantio à colheita é mais extenso, possibilitando, geralmente, uma safra por ano, além de exigir maiores extensões de terras e maior investimento financeiro e de trabalho. 
A maior parte dos agricultores produz frutas, hortaliças e/ou grãos. O agricultor Nildo Caldato trabalha com agroecologia desde 2006, é o único a produzir cana-de-açúcar agroecológica em Itapejara, sua produção é singular quando comparada aos demais, e não possui dificuldades para comercializar os derivados da cana (cachaça e açúcar mascavo). A cana é beneficiada na propriedade, em uma pequena agroindústria artesanal. Em todo o processo de beneficiamento nada é perdido, até mesmo a palha da cana é utilizada como cobertura de solo.

O agricultor destacado anteriormente, era produtor integrado de fumo e com a produção orgânica deixou esse tipo de cultivo e ampliou a produção de hortaliças, ele possui doze estufas, com produção mensal de até cinco mil pés. O mesmo indica pretender expandir a produção com a construção de mais oito estufas.

A construção da agroindústria e a aquisição das estruturas para as estufas foram feitas através da CRESOL, com recursos financiados pelo Programa Nacional de Fortalecimento da Agricultura Familiar (PRONAF). Este programa financia projetos para aos agricultores familiares e assentados da reforma agrária. Todos os produtores estudados utilizam ou já utilizaram este programa que, segundo alguns deles, tem baixas taxas de juros nos financiamentos rurais, seja para investimento em máquinas, equipamentos ou infra-estrutura, seja para custeio.

Na produção animal agroecológica, o leite e o queijo são os principais produtos que, diferentemente da renda da uva, que é por safra, a produção leiteira garante uma renda mensal para a família. No Sudoeste do Paraná, não existe nenhum laticínio que beneficie o leite produzido ecologicamente, desta forma, os produtores acabam vendendo como leite convencional, assim não recebendo nenhum adicional pela produção diferenciada. Assim, o leite é comercializado com os laticínios Latco (núcleo de Francisco Beltrão) e Alto Alegre (núcleo de Verê).

É importante destacar que embora as práticas sejam denominadas como agroecológicas, as propriedades estudadas não se enquadram no conceito de agroecologia, sendo que a única que pode ser considerada efetivamente como tal é a do agricultor Antonio Plucinski, as demais são parcialmente agroecológicas ou orgânicas, como ocorre com o agricultor Raul Dall'Agnol.

\section{A PROPRIEDADE EXCLUSIVAMENTE AGROECOLÓGICA}

Antonio Plucinski trabalha com agroecologia desde 2004, de todas as propriedades que estudamos (Figura 1), esta é a menor em termos de área e como afirmamos a única exclusivamente agroecológica, são 4,8 ha de terras, onde trabalham principalmente a esposa e ele, pois os filhos estudam em outro município.

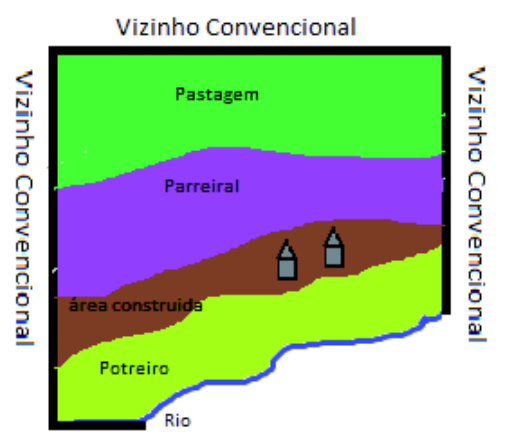

Figura 1 - Croqui: Propriedade Antonio Plucinski

Fonte: Assesoar, 2007. Organização/digitalização: SOUZA, P. 2010. 
O agricultor possui um parreiral composto por três mil pés de uvas do tipo Concord (também conhecida como francesa). Na penúltima safra (2008/2009), foram colhidos $3.319 \mathrm{~kg}$ de uva, dos quais, parte foi vendida para a fábrica de sucos Viry e parte transformada artesanalmente em vinho. O suco é certificado pela Rede Ecovida, por meio da APAV.

Antonio também possui áreas de pastagens temporárias e potreiro, destinadas para o gado leiteiro, são dez vacas de leite que produzem aproximadamente 1.800 litros/mês, comercializados em média por R $\$ 0,67$ ao litro, com o Laticínio Alto Alegre, de Vêre. Além das vacas de leite, ele possui algumas galinhas para autoconsumo. Apesar de pequena, a propriedade possui uma pequena área preservada de mata nativa junto ao rio e ao potreiro. E na área construída há uma casa, um chiqueiro e um estábulo, onde as vacas são ordenhadas.

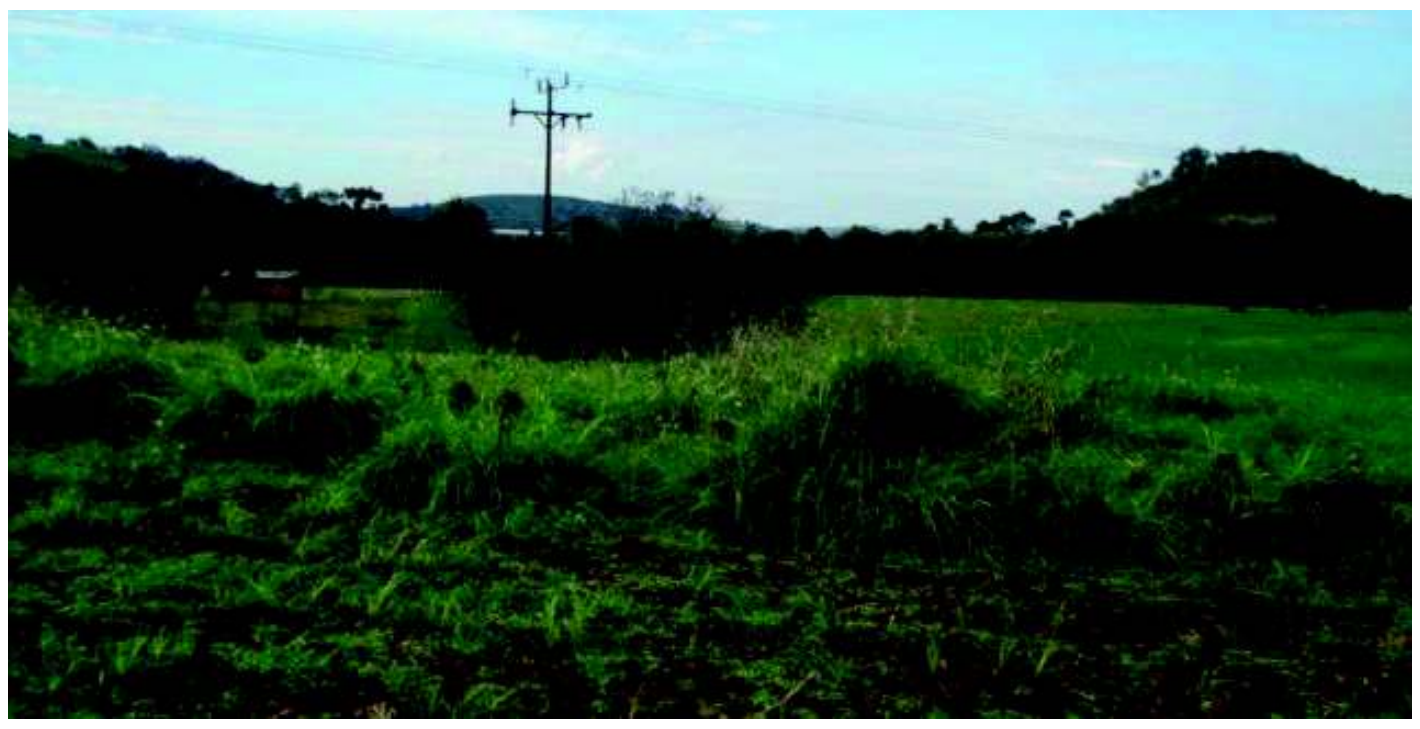

Figura 2 - Propriedade de Raul Dall'Agnol: área de pastagem

Fonte: Pesquisa de campo, 2009.

\section{A PROPRIEDADE ORGÂNICA}

Verificamos a presença de estabelecimento totalmente orgânico, como é o caso do agricultor Raul Dall'Agnol, cultivado desta forma desde 1994. São 13,0ha, onde trabalham ele, a esposa e um dos filhos. Suas principais produções são frutas, grãos (soja e milho) e leite. Raul Dall'Agnol comercializa a soja com a Agrorganica, através desta, ele adquiriu a certificação do Instituto Biodinâmico de Desenvolvimento Rural (IBD). A empresa existe desde 1998 e possui sede em Campo Largo-PR, ela compra apenas soja orgânica que é exportada para a Holanda. Toda soja exportada pela empresa é oriunda de uma usina canavieira de São Paulo (planta soja na entressafra da cana-de-açúcar) e de produtores orgânicos do Paraná.

Uma das exigências do IBD para a certificação, é que toda a propriedade seja orgânica. Dessa forma, Raul comercializa apenas a soja orgânica com a Agrogânica, de acordo com o produtor o preço é bom, na safra 2008/2009, chegou a receber $70 \%$ a mais do que a soja convencional. Já o milho, por exemplo, 
apesar de ser orgânico, é comercializado como se fosse convencional com a Cooperativa Agropecuária Sudoeste Ltda (Coasul), pois a Agrorganica não adquire este produto.

Na produção animal, destaca-se o leite orgânico, também comercializado como se fosse convencional com a Cooperativa Latco, de Francisco Beltrão. Além do leite, possuem bovinos, aves caipiras, ovos, peixes e frutas, mas apenas para o consumo familiar.

\section{AS PROPRIEDADES PARCIALMENTE AGROECOLÓGICAS}

São aquelas que possuem parte das terras manejadas de forma agroecológica e parte cultivada de forma convencional. Do leque de opções de cultivos, a agroecologia está presente, na maioria das vezes, em apenas um deles. Por exemplo, numa determinada propriedade cultivam-se grãos, hortaliças e leite; as hortaliças são manejadas e comercializadas no moldes da agroecologia; simultaneamente, a produção de grãos e leite é produzida nos moldes convencionais, tornando, assim, a propriedade parcialmente agroecológica. Este é o caso dos produtores: Osmar Franciscon, Nildo Caldato, Nelson Savitski, Nadir Antonioli, Arsindo Colla, Filisbino Cirino dos Santos e Milton Moschen (Tabela 2).

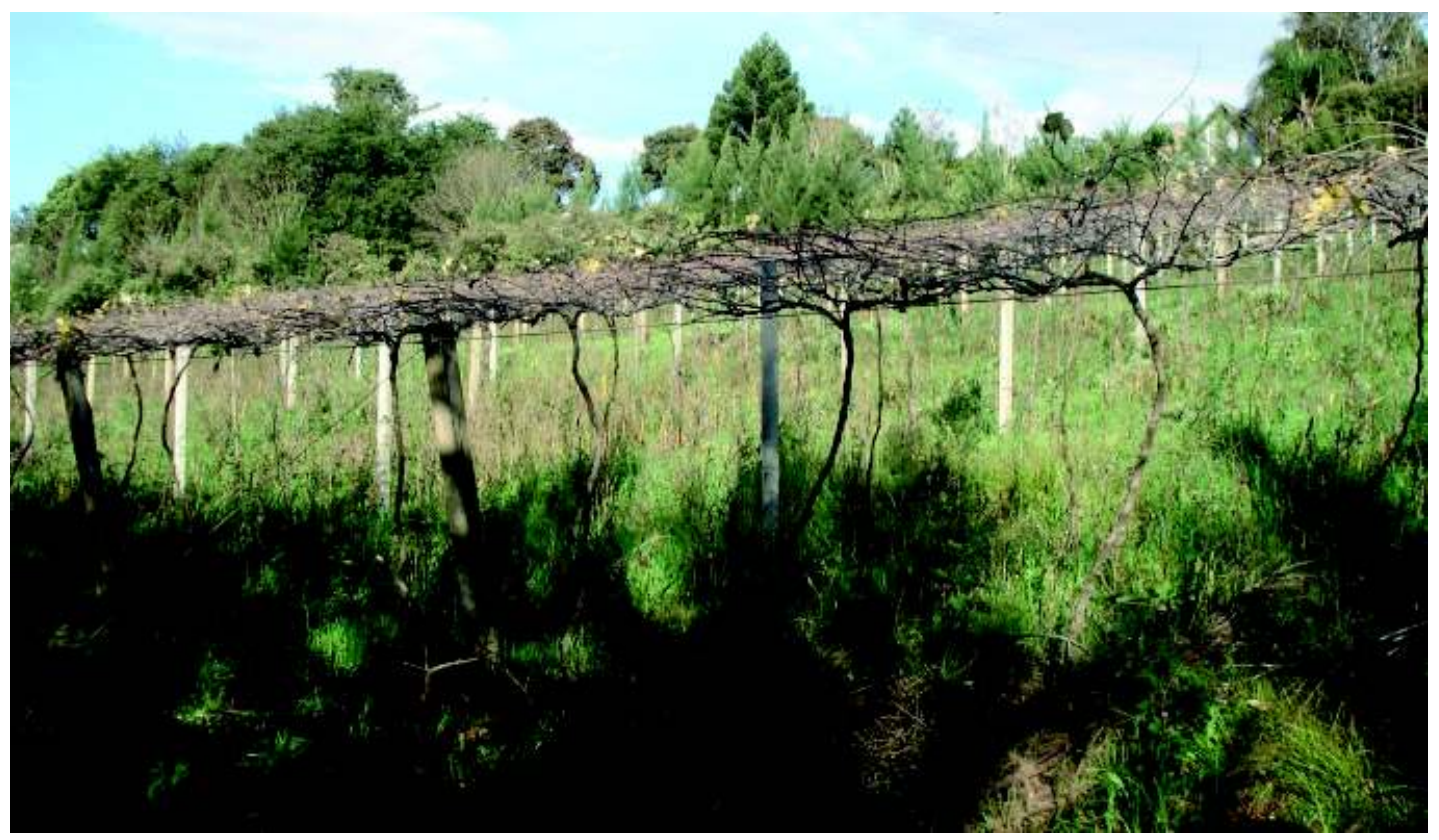

Figura 3 - Propriedade de Arsindo Colla - parreiral com barreiras verdes nas laterais.

Fonte: Pesquisa de campo, 2009.

Dentre as culturas convencionais há predomínio de grãos, como trigo, soja, milho e feijão, e na produção animal, de leite e frango (sistema de integração com a empresa Anhambi de Itapejara). A maior parte das áreas cultiváveis da propriedade é utilizada para a produção convencional. A separação da produção convencional da agroecológica é feita por barreiras verdes (foto 2), que impedem o contato entre as duas culturas e a contaminação de agrotóxicos pelo ar. 
A gestão de toda propriedade de forma agroecológica demanda muito tempo e força de trabalho, quando iniciam esta produção as famílias esperam retorno imediato, o que muitas vezes não ocorre. $\mathrm{O}$ período de transição do cultivo convencional para a produção agroecológica demanda pelo menos três anos (período de conversão ) para gerar resultados, antes deste período alguns produtores desanimam e, gradativamente, vão abandonando a produção, como é o caso do produtor Nelson Savitski.

Diante das dificuldades vinculadas à produção agroecológica, Nelson acabou desmotivando-se, isso refletiu na safra 2008-2009 de uvas. Em uma área de 1,00ha de parreiral colheu dois mil quilos de uvas, já o produtor Arsindo Colla, com a mesma área e na mesma safra, produziu quatorze mil quilos de uva, ou seja, doze mil quilos a mais.

Este desânimo levou Nelson a procurar alternativa. Atualmente, ele, a esposa e o filho mais jovem cuidam de aviários em outra propriedade. No seu estabelecimento, deixou o filho mais velho cuidando da plantação de uvas e arrendou para terceiros a pequena área de lavoura convencional que possui.

Além das implicações do uso intensivo de mão-de-obra, outra exigência encontrada pelos produtores é a certificação da produção. A qual é realizada por empresas especializadas e cobram valores, no geral, elevados para o pequeno produtor. Há também, a certificação solidária e participativa, realizada pela Rede Ecovida, que consiste em uma relação de confiabilidade entre produtores e consumidores. No entanto, via de regra, não é reconhecida pelo mercado.

\section{A CERTIFICAÇÃO DA PRODUÇÃO}

O selo agroecológico de certificação é uma garantia que os consumidores têm de que o produto que está adquirindo foi produzido em conformidade com a lei, de forma ecológica, sustentável, e principalmente, livre de agrotóxicos. Para os produtores é um elemento que facilita a comercialização e agrega valor aos produtos. Em Itapejara d'Oeste, dos produtores pesquisados, alguns possuem o selo, outros estão em processo de conversão, mas a maior parte ainda não possui, como mostra a figura 4 .

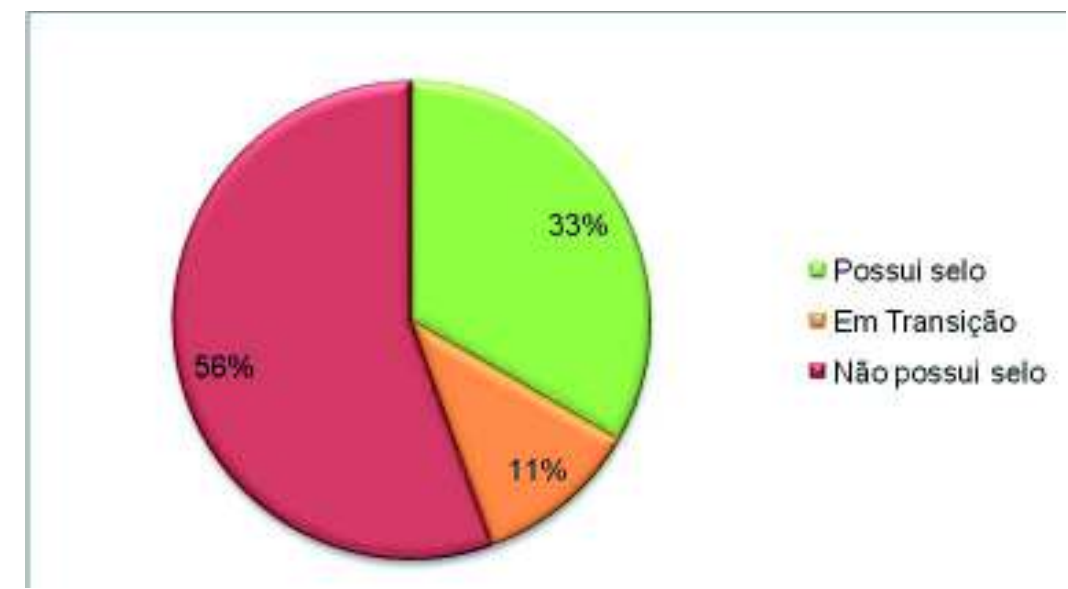

Figura 4 - Gráfico: Produtores que possuem certificação em Itapejara d'Oeste

Fonte: Pesquisa de campo, 2009.

No Brasil, como já destacamos, existem duas formas de o produtor adquirir o selo de conformidade orgânica: através de organismos de avaliação de conformidade, registrados no INMETRO e credencia-

Revista da ANPEGE. v. 6, 2010 (jan./dez.) 
dos junto ao Ministério da Agricultura e Abastecimento (MAPA), e por meio do Sistema Participativo.

No primeiro, o organismo de avaliação faz a auditoria, avalia e fornece o selo de certificação para as unidades produtoras, como é o caso do IBD. Em Itapejara d'Oeste, o produtor Rau Dall'Agnol, citado anteriormente, possui o selo IBD, certificado através da Agrorganica.

O sistema participativo é uma organização associativa ou cooperativa, que assume a responsabilidade pelas atividades de verificação e avaliação da conformidade das unidades atendidas, num Sistema Participativo de Garantia, como é o caso da Rede Ecovida. Em Itapejara são dois os produtores que possuem este selo: Arsindo Colla e Milton Moschen, além de Nadir Antonioli que está em processo de conversão.

A Rede Ecovida surgiu na década de 1980, a partir da cooperação de entidades, ONGs, produtores e consumidores do Sul do Brasil que visavam favorecer a produção de alimentos de forma sustentável. Para o fortalecimento dessas cooperações, criam-se os núcleos regionais interligados formando a Rede. Atualmente, esta possui 24 núcleos, todos na região Sul do Brasil, um deles está no Sudoeste do Paraná e oferece apoio aos agricultores para a obtenção do selo.

\section{A COMERCIALIZAÇÃO DA PRODUÇÃO}

Os agricultores não possuem dificuldades quanto à comercialização, tudo o que é produzido é vendido e em muitas vezes a procura é maior que a oferta. Parte da produção agroecológica é adquirida pelo Programa de Aquisição de Alimentos (PAA) ou comercializada no Mercado do Produtor, no caso dos grãos, a soja é comercializada com a Agrorganica.

O reconhecimento e a demanda pela produção agroecológica, embora exista, não consegue supranda as dificuldades para aumentar a produção e por isso, em muitos casos, não recebem o devido incentivo, por exemplo a Cooperativa de Comercialização da Agricultura Familiar Integrada (Coopafi) e o Mercado do Produtor, assim como o Sindicato dos Trabalhadores Rurais (STR), buscam apoiar a agricultura familiar como um todo, não diferenciando produtores agroecológicos ou convencionais. Mesmo dentro da estrutura física do Mercado, por exemplo, não existe a separação dos produtos agroecológicos dos demais.

A Coopafi está presente em mais de 25 municípios do Sudoeste, seu objetivo é organizar a produção e a comercialização. Começou atuar em Itapejara organizando uma feira municipal para estabelecer um ponto fixo para a comercialização dos produtos, porém, com o aumento da demanda dos consumidores, edificou-se o Mercado do Produtor. O objetivo do Mercado é comercializar os produtos dos agricultores familiares. A Coopafi possui setenta e cinco sócios em Itapejara, dos quais quarenta entregam produtos no Mercado, e destes, três são produtores orgânicos.

A partir do Mercado, pretende-se elaborar um programa específico para a agroecologia, porém, faltam os produtores interessados e a assistência técnica. De acordo com o responsável, os produtores preferem vender no mercado convencional, pois o pagamento pelos produtos é realizado na hora. Já o Mercado do produtor não consegue fazer o mesmo porque não tem capital de giro.

\section{VANTAGENS E DIFICULDADES DA PRODUÇÃO AGROECOLÓGICA}

Para os agricultores pesquisados, consumir alimentos saudáveis e livres de agrotóxicos é o motivo principal que levou à adesão ao sistema de produção agroecológica ou mesmo pelo orgânico (figura 5).

Percebe-se que eles optam por esta produção, em primeiro lugar, pensando na família, tanto no consumo de alimentos saudáveis como na geração de uma renda complementar, além disso, apontam que os insumos são mais baratos, não há risco de contaminação dos trabalhadores e a produção tem mercado garantido. No entanto, falta orientação técnica, cooperação entre os produtores, incentivos públicos, financiamentos específicos, mão-de-obra (há envelhecimento da população rural) e conhecimentos (técnicas e métodos) 
agroecológicos. São fatores econômicos, políticos e culturais que condicionam diretamente e limitam a produção agroecológica em Itapejara e noutros municípios.

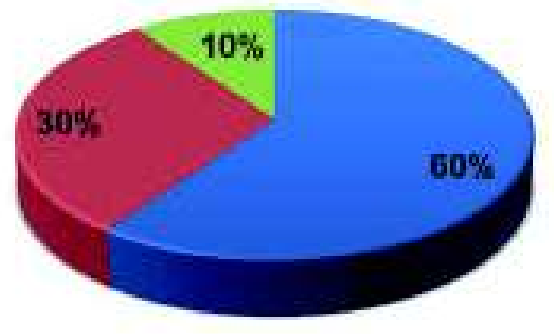

\section{Beneficios a saúde e ao meio ambiente \\ Agregar valor aos produtos}

uGeração de empregos

Figura 5 - Gráfico: Motivos de adesão à prática agroecológica

Fonte: Pesquisa de campo, 2009.

Como vimos, essa forma de produção necessita de maior estruturação e de uma organização em rede, para verificar tal estrutura, durante a pesquisa de campo, buscamos saber quais são as entidades parceiras, ou seja, as instituições que, de alguma forma, atuam (ou atuaram) incentivando e promovendo a agroecologia no município (figura 6). O CAPA e a CRESOL, como pode ser observado no gráfico 3, são as que mais se destacam no cenário agroecológico, sendo as entidades que fornecem assistência técnica e financeira aos produtores.

O CAPA, citado anteriormente, é indicado pelos produtores como referência para a assistência técnica e como entidade que incentiva e organiza os produtores, no entanto, o núcleo de Verê, é responsável por toda a região Sudoeste do Paraná, e possui poucos técnicos, dessa forma não tem capacidade para atender satisfatoriamente todos os produtores.
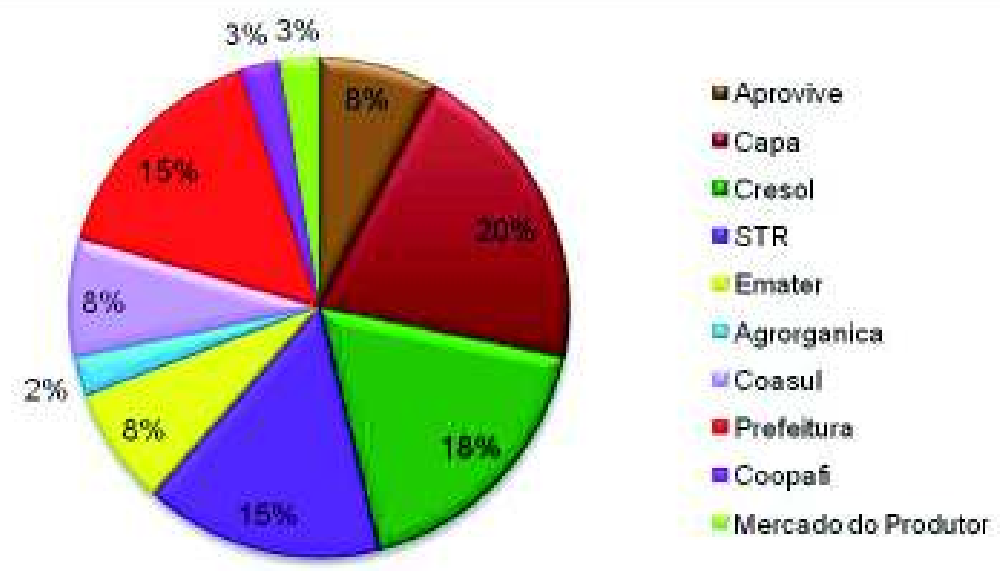

Figura 6 - Gráfico: Entidades parceiras na produção agroecológica em Itapejara

Fonte: Pesquisa de campo, 2009

Revista da ANPEGE. v. 6, 2010 (jan./dez.) 
Não bastassem as dificuldades com assistência técnica, de acordo com os depoimentos dos produtores, eles carecem também de incentivos financeiros. A CRESOL possui uma linha de crédito de investimento na produção orgânica ou agroecológica, podem acessar esta linha de crédito os agricultores familiares que possuam algum tipo de certificação de produção orgânica ou agroecológica, ou que participem de algum programa (governamental ou não) direcionado para esta produção, no entanto, embora exista esta oportunidade, ela é pouco divulgada, fato agravado porque nem todos se enquadram nas exigências para conseguir o financiamento. As dificuldades para obter incentivos financeiros específicos não se referem apenas à produção agroecológica, trata-se de uma questão mais ampla. Os investimentos destinados à agricultura familiar são reduzidos quando comparados aos recursos direcionados para a agricultura empresarial (Quadro 1).

A programação de investimentos para a agricultura familiar, na safra 2008-2009, é cinco vezes menor, além disto, do total programado, apenas a metade dos recursos foi aplicada. Dos investimentos programados para o agronegócio, também foi aplicado pouco mais que a metade, mesmo assim, a disparidade de investimentos é muito grande.

Quadro 1. Investimentos na agricultura

\begin{tabular}{|c|c|c|c|}
\hline \multicolumn{2}{|c|}{ 2008/2009 EM MILHÕES DE REAIS } \\
\hline $\begin{array}{c}\text { Fontes de recursos } \\
\text { ou programas }\end{array}$ & $\begin{array}{c}\text { Programação } \\
\text { jul/08 a jun/09 } \\
\text { (a) }\end{array}$ & $\begin{array}{c}\text { Aplicação } \\
\text { jul/08 a mar/09 } \\
\text { (b) }\end{array}$ & $\begin{array}{c}\text { Desembolso } \\
\text { relativo (\%) } \\
\text { (b)/(a) }\end{array}$ \\
\hline Agricultura empresarial & $65.000,0$ & $44.588,0$ & 68,6 \\
\hline Agricultura Familiar(Pronaf) & $13.000,0$ & $7.343,4$ & 56,5 \\
\hline TOTAL & $78.000,0$ & $51.931,4$ & 66,6 \\
\hline
\end{tabular}

Fonte: RECOR/BACEN, BNDES, BB, BNB, BASA, BANCOOB e SICREDI.

Se mensurarmos as vantagens e as dificuldades, quantitativamente, na produção agroecológica de Itapejara, há mais dificuldades, porém, tratando-se esta questão qualitativamente, os benefícios proporcionados por ela são mais amplos, especialmente porque a quantidade sem qualidade não convém para a saúde das pessoas e proteção do ambiente.

\section{AÇÕES DO PROJETO: realizadas e em andamento}

Na primeira fase de pesquisa buscamos identificar os produtores agroecológicos, a produção, as perspectivas e as dificuldades enfrentadas tanto pelos agricultores como pelas entidades parceiras. Os trabalhos de campo nas propriedades e os encontros com as instituições foram muito importantes nesta etapa, pois a partir destes, obtivemos uma caracterização mais detalhada da realidade da produção agroecológica, e a partir disso, conseguimos definir ações prioritárias em conjunto com os agricultores e com as entidades parceiras.

Com a caracterização da produção agroecológica, elaboramos alguns mapas temáticos dos municípios onde atuamos, estes mapas contêm a localização das propriedades e as respectivas produções, e 
será publicado em uma "cartilha" informativa que está sendo confeccionada. Por meio desta "cartilha", intitulada Agroecologia e consumo consciente (ALVES, Adilson et al, 2010), visamos chamar a atenção do consumidor sobre a importância do consumo de alimentos saudáveis e divulgar as produções dos municípios. Com a "cartilha" e os mapas, os consumidores terão informações pontuais sobre cada propriedade e o acesso a elas.

Paralelamente a essas atividades, programamos ações, as quais, algumas destas já foram efetivadas e outras estão planejadas para serem concretizadas durante o ano de 2010.

Dentre as atividades realizadas, destaca-se a participação na definição de objetivos no Plano de Desenvolvimento Municipal de Itapejara d'Oeste, quando assumimos o compromisso de efetivar ações voltadas ao processo produtivo agroecológico e auxiliar no levantamento do patrimônio histórico cultural do municipal.

O Plano de Desenvolvimento Municipal é um programa elaborado pelas entidades (ATER, CRESOL, Claf, Coopafi, STR, Emater, Secretaria Municipal da Agricultura), este programa possui uma série de projetos voltados para o desenvolvimento do município nos mais diversos setores (agroecologia, coleta de lixo, alimentação, saúde, administrativo, moradia etc.).

Nas ações de nosso projeto voltadas à agroecologia, organizamos cursos de capacitação, tais como: Manejo de solo e água; Manejo e cultivo de frutíferas; Pós-colheita e rotulagem, todos direcionados aos agricultores e técnicos dos municípios de Itapejara, Verê e Salto do Lontra.

Os membros da equipe também têm participado freqüentemente de diferentes eventos. Recentemente, participamos, em Itapejara, da $1^{\text {a }}$ ExpoIta, colaborando com a organização de um café colonial com produtos oriundos da agricultura familiar. Participamos também de outros eventos, como o IV SINGA (Simpósio Internacional de Geografia Agrária) e V SINGA (Simpósio Nacional de Geografia Agrária), que aconteceram simultaneamente em Niterói/RJ, em 2009, socializando e debatendo os resultados obtidos no projeto.

A participação nos eventos se dá, principalmente, através de apresentação de trabalhos referentes ao projeto, não apenas para divulgá-lo, mas também como meio de ampliar as discussões e contribuir para a difusão da agroecologia, visto que a produção acadêmica é um importante instrumento para fortalecer correntes e pressionar para a criação de políticas públicas mais justas, que contribuam para aumentar a sustentabilidade e a autonomia dos agricultores familiares.

O projeto tem previsão de conclusão das atividades previstas até dezembro deste ano (2010): estamos planejando outros cursos, tais como Cultivo e conservação de hortaliças, e Higiene familiar. Também, estamos tentando contribuir para reorganizar o Mercado do Produtor de Itapejara e, pelo segundo ano consecutivo, participaremos da Jornada Agroecológica, evento que reúne agricultores familiares de vários países da América Latina. Nossa equipe contribui participando da organização, aproveitando as atividades do evento, como as palestras e oficinas. Outrossim, estamos nos organizando para participar do VIII Colóquio de Transformações Territoriais, que acontecerá em Buenos Aires (2010) e do XX ENGA (Encontro Nacional de Geografia Agrária), a ser realizado em Francisco Beltrão (2010), sempre, apresentando, debatendo e publicando os resultados obtidos por meio de nosso projeto.

De forma geral, estamos trabalhando com aspectos e processos multidimensionais, isto é, da produção, comercialização, conservação, certificação e rotulagem; da organização política dos agricultores; do patrimônio histórico e da problemática ambiental. Assim, três frentes de trabalho que iniciaremos brevemente são as seguintes: orientação sobre a separação e coleta do lixo; curso sobre higiene familiar; identificação do patrimônio cultural-identitário de Itapejara d'Oeste.

Revista da ANPEGE. v. 6, 2010 (jan./dez.) 


\section{CONSIDERAÇÕES FINAIS}

Os resultados obtidos durante o processo de pesquisa e por meio da efetivação das atividades de extensão-cooperação com as entidades parceiras e com os agricultores do município, deixam claro que a produção agroecológica é efetivamente uma das possibilidades alternativas para o desenvolvimento local. Proporciona a produção de alimentos saudáveis, renda complementar para as famílias e condições bastante favoráveis à preservação do ambiente. A produção orgânica também se substantiva, consoante pudemos constatar, como uma alternativa peculiar para geração de renda e proteção do ambiente, apesar de ser direcionada, no município em questão, para o mercado externo.

No entanto, verificamos, ao mesmo tempo, que os agricultores têm sérias dificuldades para implementar estas produções, especialmente a agroecológica: a organização política é frágil em virtude da desmobilização diante das dificuldades encontradas; há descontinuidade em ações já implementadas; falta força de trabalho, orientação técnica continuada e há carência dos incentivos governamentais.

Percebemos, também, que há um mercado consumidor local que pode ser evocado e dinamizado em favor da produção agroecológica. Porém, em Itapejara d'Oeste, esta produção ainda é incipiente. Tudo que se produz é comercializado com facilidade, ou seja, falta produção regular, diversificada e certificada, bem como ações continuadas e mais focadas por parte das entidades envolvidas no processo em questão.

Isto indica que as perspectivas futuras, em curto prazo, não são muito favoráveis aos agricultores familiares agroecológicos, porém, acreditamos que há todo um conjunto de elementos territoriais que podem ser dinamizados juntamente com essa produção, como o patrimônio histórico e cultural, cachoeiras, pequenas feiras comerciais, festas típicas dos descendentes de alemães, italianos e poloneses que podem ser analisadas e organizadas de maneira que sejam valorizadas e potencializadas para gerar renda complementar, considerando, evidentemente, sua preservação ambiental e territorial.

Todos são componentes e características do território, das pessoas, revelando processos sociais e naturais mais amplos e inerentes a nossa vida cotidiana e, assim, podem ser aproveitados sem a implementação de grandes empreendimentos empresariais no espaço rural e na cidade. No entanto, isto exige uma posição política firme e bem definida por parte dos governantes locais.

\section{REFERÊNCIAS BIBLIOGRÁFICAS}

ALTIERI, Miguel. Agroecology: the scientific basis of alternative agriculture. Boulder: Westview Press, 1987.

ALTIERI, Miguel. Agroecologia: a dinâmica produtiva da agricultura sustentável. Porto Alegre: Editora da UFRGS, 1998.

ALVES, Adilson et al. Agroecologia e consumo consciente. Francisco Beltrão (PR): SETI/USF, 2010.

CAGNINI, D.; Entrevista realizada em 15 de janeiro de 2010, membro CAPA-Verê.

Entrevistas realizadas com produtores agroecológicos de Verê, Salto do Lontra e Itapejara d'Oeste, durante o ano 2009.

CAPORAL, Francisco e COSTABEBER, J. A. Agroecologia: enfoque científico e estratégico. In: Agroecologia e desenvolvimento rural sustentável, v.3, n.2, p.13-16, 2002.

FABRO, J; TONINI, F. Entrevista em 18 de maio de 2009 - ONG ASSESOAR.

GLIESSMAN, S. R. Agroecologia: Processos ecológicos em agricultura sustentável. 2ed.Porto Alegre: Ed. UFRGS, 2001.

IBGE. Banco de Dados Agregados. Senso Agropecuário 1995- SIDRA. Disponível em: http://www.ibge.gov.br. Acesso em: 06 de maio de 2010.

Revista da ANPEGE

SAQUET, M. A.; SOUZA, P.; SANTOS, R. A. 
MENASCHE, Renata. A agricultura familiar à mesa. Porto Alegre: Editora da UFRGS, 2007.

OLIVEIRA, Daniela; SANTOS, L.C.R (Org). Caderno de formação: certificação participativa de produtos ecológicos. Florianópolis: Rede Ecovida de Agroecologia, 2004.

VAN DER PLOEG, J. D. Camponeses e impérios alimentares: lutas por autonomia e sustentabilidade na era da globalização. Porto Alegre: Editora da UFRGS, 2008.

SCHNEIDER, Rome; Entrevista em 20 de julho de 2009 - CAPA-Verê.

SAQUET, Adriano et al. Agricultura ecológica e ensino superior: contribuições ao debate. Francisco Beltrão (PR): Grafit, 2005.

SAQUET, Adriano. Reflexões sobre a agroecologia no Brasil. In: CANDIOTTO, L.; CARRIJO, B.; ALVES, A. (Orgs.). Desenvolvimento territorial e agroecologia. SP: Expressão Popular, 2008. p.137-153.

SAQUET, Marcos. Abordagens e concepções de território. SP: Ex. Popular, 2007.

SAQUET, Marcos et al. A agroecologia como estratégia de inclusão social e desenvolvimento territorial. In: SAQUET, Marcos e SANTOS, Roseli (Org.). Geografia agrária, território e desenvolvimento. São Paulo: Expressão Popular, 2010. p.237-254.

SAUER, Sérgio e BALESTRO, Moisés. Agroecologia e os desafios da transição agroecológica. São Paulo: Expressão Popular, 2009a.

SAUER, Sérgio e BALESTRO, Moisés. A diversidade no rural, transição agroecológica e caminhos para a superação da Revolução Verde: introduzindo o debate. In: SAUER, S. e BALESTRO, M. (Orgs.). Agroecologia e os desafios da transição agroecológica. São Paulo: Expressão Popular, 2009b. p.7-15.

SCHMITT, Claudia. Transição agroecológica e desenvolvimento rural: um olhar a partir da experiência brasileira. In: SAUER, S. e BALESTRO, M. (Orgs.). Agroecologia e os desafios da transição agroecológica. São Paulo: Expressão Popular, 2009. p.177-203.

WILLER, Helga; KILCHER, Lukas. The World of Organic Agriculture. Statistics and Emerging Trends 2009. FIBL-IFOAM Report. IFOAM, Bonn; FiBL, Frick; ITC, Geneva Eds.2009.

Recebido em agosto de 2010 Aceito em dezembro de 2010

Revista da ANPEGE. v. 6, 2010 (jan./dez.) 